\title{
Characteristics of Speed and Acceleration in the 60- Meter Running Test Between Men's Football and Futsal Players
}

\author{
Tommy Apriantono*, Indria Herman, Agung Dwi Juniarsyah, Sri Indah Ihsani \\ Sports Science Research Group, School of Pharmacy \\ Mechanic of Engineering, Faculty of Mechanic of Aerospace Engineering \\ Institut Teknologi Bandung \\ Bandung, Indonesia \\ *tommy@fa.itb.ac.id
}

\begin{abstract}
Aim of the study: to examine and compare speed and acceleration at run $60 \mathrm{~m}$ test between football and futsal players. This study examined 10 male football players (age 15.4 years; height $164.9 \mathrm{~cm}$; body mass $59.6 \mathrm{~kg}$ ), futsal players (age 16.7 years; height $169.1 \mathrm{~cm}$; body mass $58.0 \mathrm{~kg}$ ). Each group twice runs in 60 meters, every 10 meters there is an officer who records the time. The results show that the average time to travel 60 meters is $2.42 \mathrm{~s}$ for football players and $2.36 \mathrm{~s}$ for futsal players. Player speed is $7.35 \mathrm{~m} / \mathrm{s}$ for football and $7.49 \mathrm{~m} / \mathrm{s}$ for futsal. Acceleration is $0.92 \mathrm{~m} / \mathrm{s} 2$ for football and $0.94 \mathrm{~m} / \mathrm{s} 2$ for futsal. The results of the average time, speed and acceleration showed that futsal players are higher than football players. From the data there is a similar trend from a distance of 20 to a distance of 30 which is a decrease and a slowdown in the correlation. Running speed of futsal players is higher than football players, this is because futsal players are used to the characteristics of futsal games that rely on short sprints during matches with relatively smaller fields compared to football.
\end{abstract}

Keywords: acceleration, futsal, football, running, speed

\section{INTRODUCTION}

Futsal and football are one of the sports involving physical activity that is done to train a person's body [1]. There is only a small difference between futsal and football. On the other hand, the peak of performance in field sports is having speed and acceleration in both physical and game terms. Acceleration is important for field sports athletes who need high level sprint skills [2-4].

Likewise in team sports such as futsal and football, this popular and growing sport requires good physical, technical, tactic and mental abilities [5]. One of them is the speed and acceleration in doing movements such as running, shooting and passing [6,7]. And in previous studies that futsal players in Bandung City had an average activity profile of $3.54 \%$ for jogging ( $3 \mathrm{~m} / \mathrm{s}), 27.52 \%$ for medium-speed running $(>3.1 \mathrm{~m} /$ s), $28.10 \%$ for high-speed running ( $>5.1 \mathrm{~m} / \mathrm{s}$ ) and $40.73 \%$ for maximum speed running $(>7.1 \mathrm{~m} / \mathrm{s})[8]$.

For that, knowing the running pattern of both football and futsal players is important. Measuring speed and acceleration is done with a 60 meter sprint test. In this study researchers have not found a comparison of the speed and acceleration of futsal and football players aged 16 to 17 years. Speed testing allows the trainer to be able to make training programs that are suitable for developing athletic potential. Speed testing is also a recommendation for children who want to pursue a career as an athlete in sports that are in accordance with the characteristics of sports, especially futsal and football.

\section{METHOD}

This study used observational study. The participants were classified into two group according by their types of sport: 10 were assigned to the futsal group, and the other 10 in the football group. Inclusion criteria were includes: 2 years of experience in their expertise. The research related to human use has complied with all the relevant national regulations and institutional policies, has been approved by Ethic Committee of Poltekes Bandung. The measurement in this study is to measure the time every 10 meters from 0 - 60 meters using a stopwatch, and each subject takes twice the data. And then, statistical analysis is done by determining normal distribution using Kolmogorov-Smirnov's non-parametric test. Evaluation of match analysis is done with independent and dependent $\mathrm{T}$ test using SPSS 16 for Windows, and the significance level (pvalue) is below 0.05 .

\section{RESULT}

The anthropometric data of these two subject groups are found in table1, where between football players and futsal have the same anthropometry.

TABLE I. CHARACTERISTIC OF ANTHROPOMETRY FOOTBALL AND FUTSAL PLAYERS

\begin{tabular}{|l|l|l|}
\hline \multicolumn{1}{|c|}{ Variable } & \multicolumn{1}{|c|}{ Football $(\mathbf{n = 1 0})$} & \multicolumn{1}{c|}{ Futsal $(\mathbf{n = 1 0})$} \\
\hline Age $($ years $)$ & $16,4 \pm 0,69$ & $16,7 \pm 0,48$ \\
\hline Height $(\mathrm{cm})$ & $164,9 \pm 8,38$ & $169,1 \pm 3,47$ \\
\hline Weight $(\mathrm{kg})$ & $59,6 \pm 8,19$ & $58,0 \pm 7,83$ \\
\hline
\end{tabular}

Table 2 is the average time of football and futsal players, the football player's time from $0-60$ meters is $8.50 \pm 0.36 \mathrm{~s}$, 
while the futsal players are $8.39 \pm 0.16 \mathrm{~s}$. The average time for futsal players is faster than football players. Likewise, the average time is every 10 meters, even though it is not significantly different $(\mathrm{p}>0.05)$.

TABLE II. AVERAge Time Football and Futsal Players

\begin{tabular}{|c|c|c|}
\hline \multirow{2}{*}{ Distance (m) } & \multicolumn{2}{|c|}{ Average Time (s) } \\
\hline & Football $(n=10)$ & Futsal $(n=10)$ \\
\hline 10 & 2.14 & 2.15 \\
\hline 20 & 3.35 & 3.34 \\
\hline 30 & 4.77 & 4.72 \\
\hline 40 & 6.09 & 6.01 \\
\hline 50 & 7.35 & 7.23 \\
\hline 60 & 8.51 & 8.38 \\
\hline Average $10 \mathrm{~m}$ & 2.42 & 2.36 \\
\hline
\end{tabular}

TABLE III. Average SPEEd Football AND FutSAL Players

\begin{tabular}{|c|c|c|}
\hline \multirow{2}{*}{ Distance (m) } & \multicolumn{2}{|c|}{ Average speed $(\mathrm{m} / \mathrm{s})$} \\
\hline & Football & Futsal \\
\hline 10 & 4.68 & 4.65 \\
\hline 20 & 8.24 & 8.40 \\
\hline 30 & 7.02 & 7.27 \\
\hline 40 & 7.60 & 7.76 \\
\hline 50 & 7.95 & 8.17 \\
\hline 60 & 8.62 & 8.70 \\
\hline Average $10 \mathrm{~m}$ & 7.35 & 7.49 \\
\hline
\end{tabular}

The average speed of futsal players in 10 meters is at 7.49 $\mathrm{m} / \mathrm{s}$ while for football players is at $7.35 \mathrm{~m} / \mathrm{s}$ but not significantly different $(p>0.05)$. Table 3 , peak speed trends at a distance of 20 meters, decreased at 30 meters, and again increased until at a distance of 60 meters. In this study, futsal and football players have the same tendency that is a decrease in speed when running at a distance of 20 to 30 meters.

In theory that at a distance of $0-30$ meters is the acceleration phase of an athlete, 30-60 meters is the maximum speed phase, and 60-100 meters is the phase of maintaining speed. Both futsal players and football players cannot maximize acceleration to a 30 meter limit, especially for futsal players with relatively small field sizes that make players unable to produce maximum speed such as sprinter runners, due to the characteristics of futsal games that have a lot of short distance running, with fast situations change.

Likewise in acceleration, acceleration is a derivative of speed with time. Table 4 , the average acceleration of futsal players in 10 meters is $0.94 \mathrm{~m} / \mathrm{s} 2$, this value is higher than the football players who have an acceleration of $0.93 \mathrm{~m} / \mathrm{s} 2$ but not significantly different ( $p>0.05$ ). Peak acceleration for both futsal and football players is at 20 meters, although futsal players are $3.16 \mathrm{~m} / \mathrm{s} 2$ and $2.93 \mathrm{~m} / \mathrm{s} 2$ for football players but not significantly different $(\mathrm{p}>0.05)$.
TABLE IV. AVERAge ACCELERAtion Football ANd Futsal Players

\begin{tabular}{|l|l|l|}
\hline \multirow{2}{*}{ Distance (m) } & \multicolumn{2}{c|}{ Acceleration (m/s2) } \\
\cline { 2 - 3 } & \multicolumn{1}{|c|}{ Football } & \multicolumn{1}{c|}{ Futsal } \\
\hline 10 & 2.19 & 2.16 \\
\hline 20 & 2.93 & 3.16 \\
\hline 30 & -0.85 & -0.82 \\
\hline 40 & 0.44 & 0.38 \\
\hline 50 & 0.28 & 0.33 \\
\hline 60 & 0.58 & 0.46 \\
\hline Average $10 \mathrm{~m}$ & 0.93 & 0.94 \\
\hline
\end{tabular}

\section{DISCUSSION}

In this study the average time, speed, and acceleration of futsal players are higher than football players. And the results of this study indicated that there were no significant differences in the time $\mathrm{T} 0-60 \mathrm{~m}$ between the groups of football and futsal players $(\mathrm{p}>0.05)$

Factors that cause futsal players to have higher the average time, speed and acceleration than football players are due to differences in game characteristics. Futsal is an intermittent sport with high intensity, with an activity profile of $40 \%$ in a maximum-speed running $[2,8,9]$ and this can be caused by a limited distance with the speed transition from defending to attack and vice versa, which results in high intensity $[3,10]$. While the football game is in moderate intensity and $70 \%$ an activity profile in jogging. In addition, the peak speed and acceleration trends in the 10-20 meter section are the same as in the previous study the field players reached higher maximum velocities in the 10-20 m section [4].

This study provides data that can be used by coaches to make a more complete assessment of their players' physical level profiles with regard to the quality of their speed. However, coaches from these sports should also develop accelerative practices that involve turns.

\section{CONCLUSION}

We demonstrate that, running speed of futsal players is higher than football players. This phenomenon can be explained that futsal players are used to the characteristics of futsal games that rely on short sprints during matches with relatively smaller fields compared to football. We encouraged all of coaches and sport scientist to generated training program of futsal and football by the characteristics of each game and physiological athlete's responds. Nevertheless, further studies are required to indicate the underlying physiological characteristics of futsal and football.

\section{ACKNOWLEDGMENT}

This research was supported by KEMENRISTEK DIKTI. We thank our colleagues LPPM ITB who provided insight and expertise that greatly assisted the research, although they may not agree with all of the interpretations/conclusions of this paper.

\section{REFERENCES}

[1] W.L. Kenney, J.H. Wilmore, D.L. Costill, "Physiology of sport and exercise," Champaign: Human Kinetics; 2012. 
[7] M. Brandes, S. Elvers, "Elite youth soccer players' physiological responses, time-motion characteristics, and game performance in 4 vs. 4 small-sided games: the influence of coach feedback," J Strength Cond Res, vol. 31(10), pp. 2652-2658, October 2017. early acceleration i n field sport athletes," in Journal of Sports Science and Medicine, vol. 2, pp. 144-150, 2003.

[3] K.D. Simperingham, J.B. Cronin, A. Ross, "Advances in sprint acceleration profiling for field-based team-sport athletes: utility, reliability, validity and limitations," Sports Med, vol. 46(11), pp. 16191645, November 2016.

[4] J.B. Caccese, T.W. Kaminski, "Minimizing head acceleration in soccer: a review of the literature," Sports Med, vol. 46(11), pp. 1591-1604, November 2016.

[5] T. Stølen, K. Chamari, C. Castagna, U. Wisløff, "Physiology of soccer: an update," Sports Med, vol. 35(6), pp. 501-36, 2005.

[6] I. Helmich, "Game-specific characteristics of sport-related concussions. J Sports Med Phys Fitness," vol. 58(1-2), pp. 172-179, January-February 2018.

[8] C. Castagna, \& J. C. B. Alvarez, "Physiological demands of an intermittent futsal-oriented high-intensity test," The Journal of Strength \& Conditioning Research, vol. 24(9), pp. 2322-2329, 2010.

[9] C. Castagna, S. D’Ottavio, J. G. Vera, \& J. C. B. Álvarez, "Match demands of professional Futsal: a case study," Journal of Science and medicine in Sport, vol. 12(4), pp. 490-494, 2009.

[10] R. S. Oliveira, A. S. Leicht, D. Bishop, J. C. Barbero-Álvarez, \& F. Y. Nakamura, "Seasonal changes in physical performance and heart rate variability in high level futsal players," International journal of sports medicine, vol. 34(05), pp. 424-430, 2013. 